\title{
Buschke-Lowenstein Tumor of the Vulva: A Case Report
}

\section{Moukhlis S*, Wajih O, Ouafidi B, Boufettal H, Mahdaoui S and Samouh N}

Gynecology department, University Hospital Ibn Rochd, Faculty of Medicine and Pharmacy of Casablanca, Hassan II University,

Casablanca, Morocco

*Corresponding author: Moukhlis S, Residence Les Hills, Tranche 2, Building F, Apartment 6, Sidi Maarouf, Casablanca, Morocco, Tel : +212 600882164 , E-mail: sabah.moukhlis@gmail.com

Citation: Moukhlis S, Wajih O, Ouafidi B, Boufettal H, Mahdaoui S, et al. (2021) Buschke-Lowenstein Tumor of the Vulva: A Case Report. J Case Rep Stud 9(2): 201

Received Date: June 14, 2021 Accepted Date: August 05, 2021 Published Date: August 07, 2021

\begin{abstract}
Buschke-Lowenstein tumor or giant condyloma acuminata is a rare disorder of the external genitalia, belonging to the group of verrucous carcinomas, and usually affects immunocompromised men. Human Papillomavirus (HPV) 6 and 11 are potentially involved in the pathophysiology. A detailed questioning, a rigorous clinical examination and complementary imaging are important to establish an accurate lesion assessment and an adapted management. Wide surgical excision is the treatment of choice.
\end{abstract}

Keywords: Buschke-Lowenstein Tumor; Giant Acuminated Condyloma; HPV 


\section{Introduction}

Buschke-Lowenstein tumor (BLT) or giant condyloma acuminata (GCA) is a rare manifestation of human papillomavirus (HPV) infection, affecting the genital area and transmissible mainly through sexual contact. It is characterized by surface and deep extension without invasion of the basement membrane, by its degenerative potential, and by its recurrent character after treatment [1]. It is a slow-growing tumor which, despite its benign histopathological appearance, is clinically malignant due to its locally destructive nature and its tendency to recur. We report a rare case of a 30-year-old woman presenting a Buschke and Lowenstein tumor of the vulva. Through this case report, we will discuss the diagnostic and therapeutic particularities of these rare tumors.

\section{Case report}

A 30-year-old woman, sexually active, without any notion of multiple partners. She presented with a vulvar swelling that had been evolving for one year, progressively increasing in size, responsible for functional discomfort and delicate hygiene. The clinical examination revealed a lesion of greyish color, vegetative, budding in cauliflower, taking the two labia, with no infiltration of the base, or associated bleeding (Figure 1). The vaginal intoitus and the urethral meatus were respected. Speculum examination was normal. Examination of the lymph nodes did not reveal any palpable adenopathy. The vulvar biopsy showed a vulvar condyloma acuminata. Pelvic ultrasound, Pap smear and STD testing did not reveal any abnormalities. A large surgical excision was indicated, removing the condyloma (Figures 2 and 3). The final anatomopathological examination revealed a hyperplastic epidermis with a verrucous appearance, marked exocytosis, with neutrophils, surmounted by a parakeratosis and full of koilocytes. The cells were moderately atypical with the presence of binucleations and some mitoses. The chorion was fibrous with vascular congestion and a discrete inflammatory infiltrate essentially mononuclear without dysplasia or invasion of the chorion, thus concluding to a giant accumulated condyloma. With a two-year follow-up, no recurrence was observed.

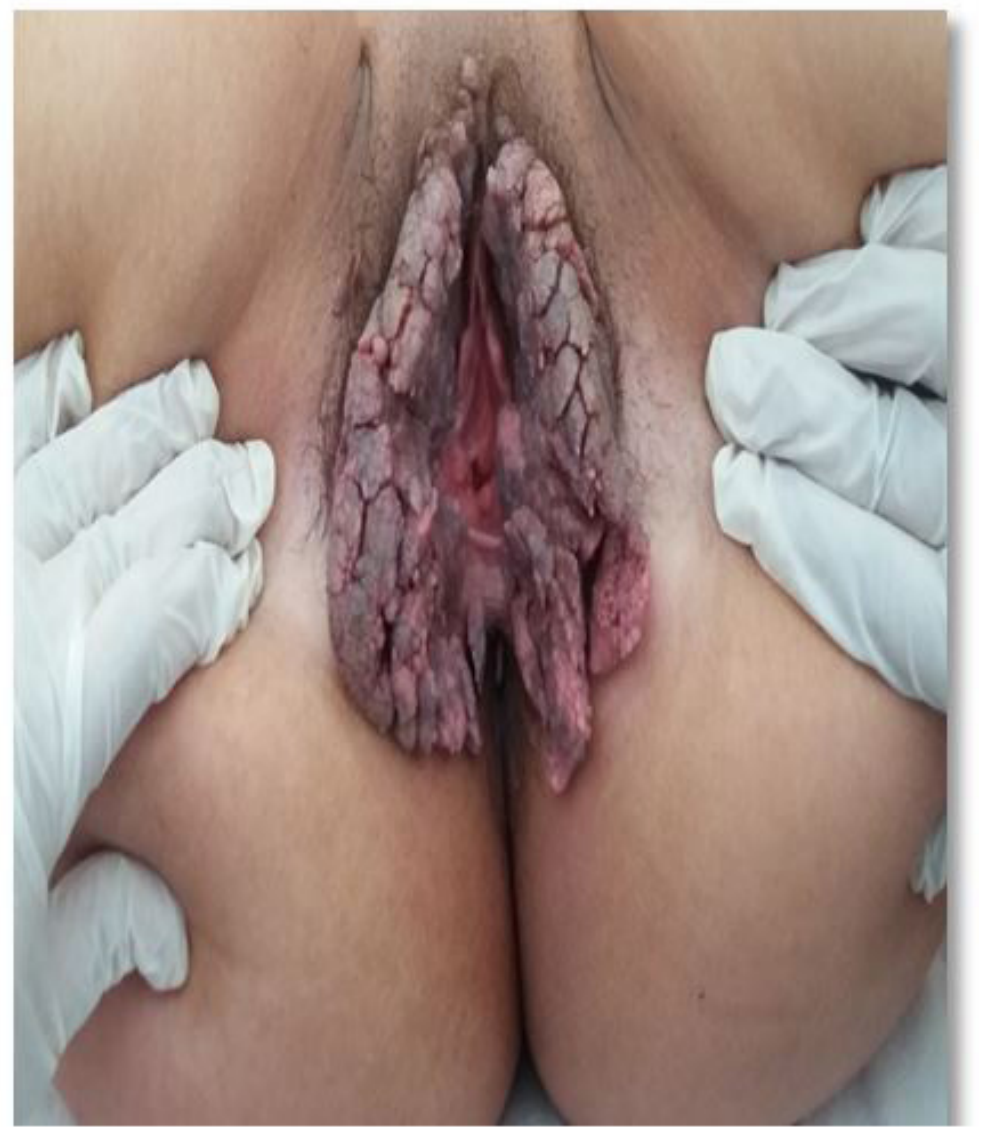

Figure 1: Tumor taking over both labia majora 


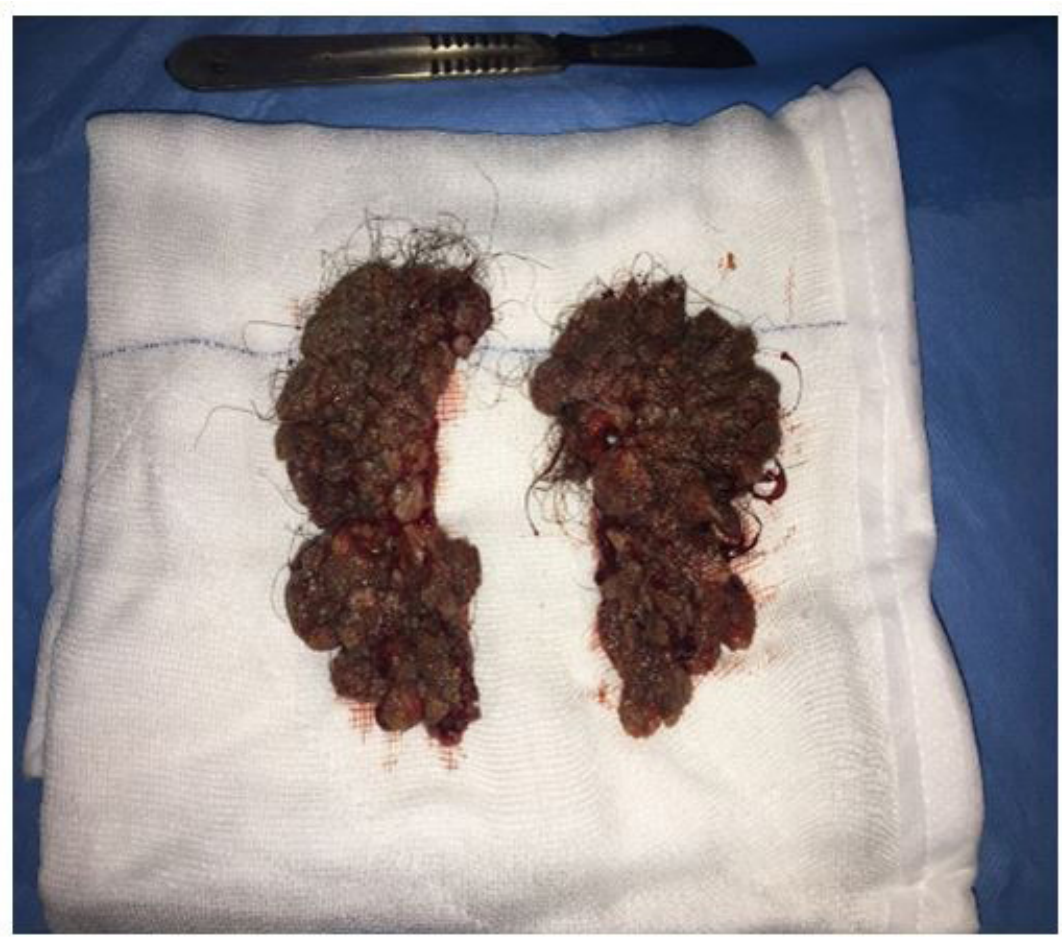

Figure 2: Large excision of the labia

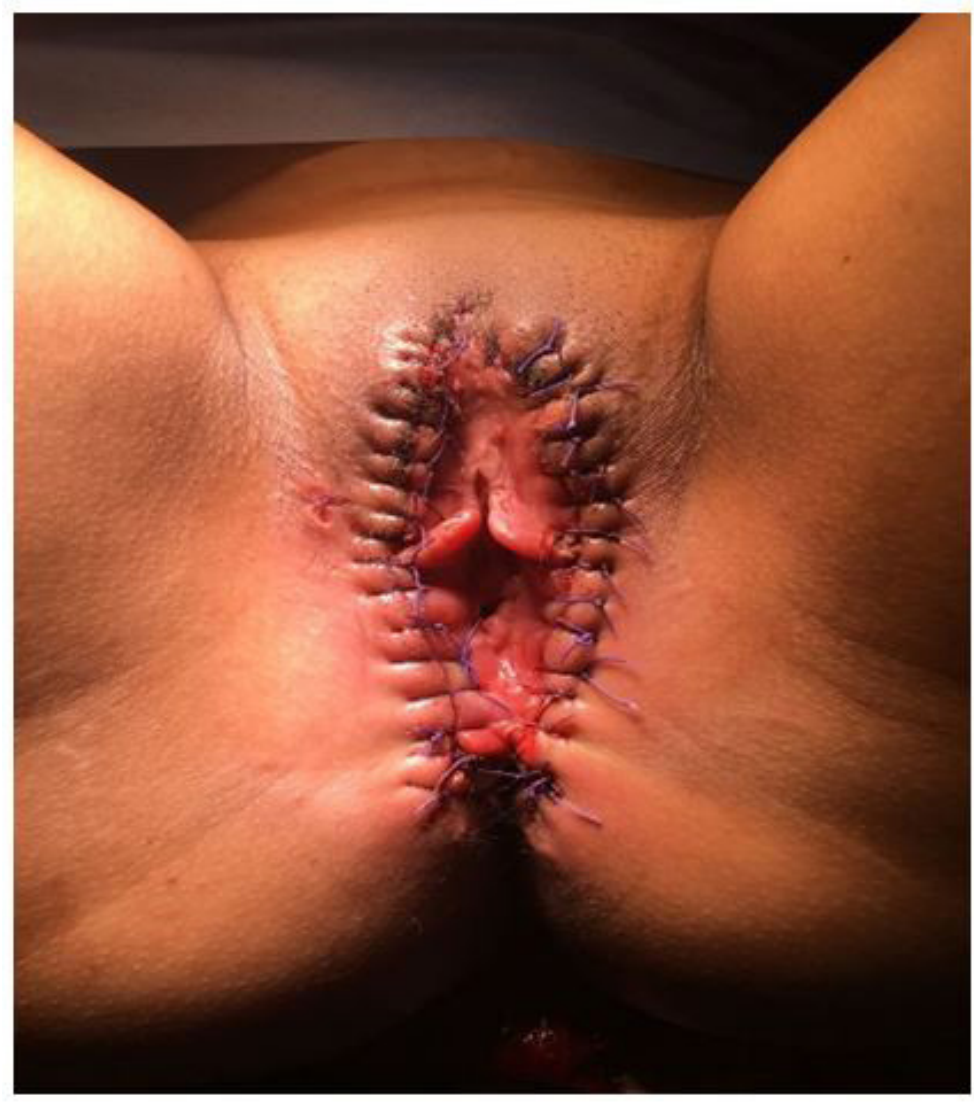

Figure 3: Immediate result after surgery 


\section{Discussion}

Giant accumulated condyloma (GAC) was first described by Buschke and Lowenstein in 1925 on a male patient. Buschke-Lowenstein tumor (BLT) is a rare disorder. Its incidence is estimated to be about $0.1 \%$ in the general population [2]. It is a manifestation of Human Papillomavirus (HPV) infection of the external genitalia. The low-risk serotypes 6, 11 are the most frequently associated. However, it can be associated with the high-risk subtypes (16 and 18) [3]. The risk factors associated with the onset and development of TBL are mainly sexual risk behaviors: sexually transmitted infections (STIs), multiple sexual partners, homosexuality; immunosuppression (immunosuppressants drugs, HIV infection), poor perianal hygiene, pregnancy and multiparity. According to Zhenhui el al, TBL is three times more common during pregnancy.

Buschke-Lowenstein TBL can occur at almost any age, with an age average of 45 years. It affects men more often (77\%), especially in the penile and anorectal regions [4]. The preferential location of TBL for women is the vulva in $90 \%$ of cases, while the anorectal location is less frequent. Our patient was 30 years old and presented with a Buschke and Lowenstein tumor of the vulva.

The transmission is mainly sexual. It can also be transmitted through water, linen, or other soiled materials. Mother-to-child transmission occurs via the placenta or during delivery, hence the need to schedule a caesarean section and to examine any newborn of a mother with TBL [5].

Clinically, giant condylomata accumbens CAG most often begin as small, rounded or filiform lesions, pinkish or normal skin color, progressing to a large tumor, up to $10 \mathrm{~cm}$, often white or yellow, irregular, budding, cauliflower-like, with a surface bristling with vegetations, firm, hard and resistant, which may be complicated by superficial ulceration or superinfections [5]. The presence of associated foul odor is typical in TBL. The duration of evolution is variable, ranging from a few months to several years. The shorter the duration, the more immunocompromised the patient [6]. The presence of bleeding, infiltration of the base, or the presence of adenopathy should raise suspicion of malignant degeneration. The latter is estimated at $8.5 \%$ to $23.8 \%$. The most common histological type is squamous cell carcinoma $[7,8]$.

The diagnosis is based on clinical findings. However, a vulvar biopsy is essential to confirm the diagnosis and, above all, to avoid misdiagnosis of a malignant transformation. Histologically, TBL is a perfectly limited squamous cell tumor characterized by considerable epithelial hyperplasia, sometimes pseudoepitheliomatous, with the presence of pathognomonic markers of HPV infection: hyperacontosis, hyperpapillomatous and koilocytes. However, their identification is not always constant. Furthermore, the respect of the basement membrane is very important for the diagnosis, because otherwise a squamous cell carcinoma is considered [5].

Locoregional imaging (CT scan or MRI) may also be necessary to assess tumor extension and operability of the patient.

The search for other STIs is systematic and must include the partner. It includes HIV, HCV, HBV, VDRL-TPHA serologies, as well as the search for Chlamydia Trachomatis or Nesseria Gonnorhoeae by PCR in urine or even in an anal swab.

Some factors must be considered in the choice of treatment, including lesion size and thickness, anatomical site, HPV subtype, and immune status. The treatment of choice for Buschke-Lowenstein tumor is surgical with large resection, avoiding as much as possible to compromise the patient's sexual functional prognosis, as well as to prevent the occurrence of recurrence and malignant degeneration. It has been demonstrated that wide surgical excision alone allows satisfactory results to be obtained in $46 \%$ of cases $[9,10]$. Recurrence is always local, and occurs when the excision is limited or incomplete. For adjuvant treatment, Buffel et al [11] recommend a chemical or physical destroyer or immunomodulator after surgical treatment. Majeski and Jablonska advise against radiotherapy, as it promotes malignant transformation of the tumor [3]. A minimum of one year of clinical surveillance is required to ensure that there is no recurrence and no malignant transformation. 


\section{Conclusion}

Buschke-Lowenstein tumor (BLT) or giant condyloma acuminata is a rare affection of the external genitalia. Because of the anatomical location of the lesion, it requires the widest possible surgical treatment and rigorous surveillance to avoid recurrence and to detect malignant degeneration, while ensuring esthetically acceptable results. Chemotherapy and immunomodulators deserve to be better evaluated.

\section{Conflicts of interest}

No conflicts of interest. 


\section{References}

1. Ibrahimi A, Ziani I (2020) Buschke-Lowenstein tumor with penile location [Tumeur de Buschke-Lowenstein à localisation pénienne]. Pan Afr Med J 37.

2. Ahsaini M, Tahiri Y, Tazi MF, Elammari J, Mellas S, et al. (2013) Verrucous carcinoma arising in an extended giant condyloma acuminatum (Buschke-Löwenstein tumor): a case report and review of the literature. J Med Case Reports 7: 273.

3. Jablonska S (1998) Traditional therapies for the treatment of condylomata acuminata (genital warts). Australas J Dermatol 39: S2-4.

4. Patel R, Kaloucava S (2017) A case of penile Buschke-Lowenstein tumor in a developing country. Clin Case Rep 5: 257-9.

5. Cherkaoui A, Araki A, Aboutaieb R, Meziane F (2003) Giant condyloma acuminata - Buschke Lowenstein's tumor (about 3 cases) [Le condylome acuminé géant - tumeur de Buschke Lowenstein (à propos de 3 cas)]. Prog Urol 5.

6. Niazy F, Rostami K, Motabar AR (2015) Giant Condyloma Acuminatum of Vulva Frustrating Treatment Challenge. World J Plast Surg 4: 159-62.

7. Reichenbach I, Koebell A, Foliguet B, Hatier M, Mascotti J, et al. (1995) Tumeur de Buschke et lowenstein à propos d'un cas feminin. J Gynecol Obstet Biol Reprod 24: 491-5.

8. Villote J, Benhamou G, Alcabes G, Vissuzaine C, Toublanc M, et al. (1989) Tumeur de Buschke Lowenstein anorectale (condylomatose géante) nécessitant une amputation du rectum. Gastroenterologie Clin Biol 13: 105-7.

9. Muñoz N, Bosch FX, de Sanjosé S, Herrero R, Castellsagué X, et al. (2003) Epidemiologic Classification of Human Papillomavirus Types Associated with Cervical Cancer. N Engl J Med 348: 518-27.

10. von Krogh G, Lacey CJ, Gross G, Barrasso R, Schneider A (2000) European course on HPV associated pathology: guidelines for primary care physicians for the diagnosis and management of anogenital warts. Sex Transm Infect 76: 162-8.

11. Buffet M, Aynaud O, Piron D, Dupin N, Escande JP (2002) Buschke-Lowenstein penile tumor. Prog Urol 12: 332-6. 